\title{
Tapentadol Versus Tramadol: A Narrative and Comparative Review of Their Pharmacological, Efficacy and Safety Profiles in Adult Patients
}

\author{
Lucien Roulet $^{1}\left(\mathbb{D} \cdot\right.$ Victoria Rollason $^{2} \cdot$ Jules Desmeules $^{2} \cdot$ Valérie Piguet $^{2,3}$
}

Accepted: 29 March 2021 / Published online: 1 July 2021

(c) The Author(s) 2021

\begin{abstract}
We conducted a narrative review of the literature to compare the pharmacological, efficacy and safety profiles of tapentadol and tramadol, and to assess the clinical interest of tapentadol in adult patients. Tapentadol and tramadol share a mixed mechanism of action, including both mu-agonist and monoaminergic properties. Tapentadol is approximately two to three times more potent than tramadol and two to three times less potent than morphine. It has no identified analgesically active metabolite and is not significantly metabolised by cytochrome P450 enzymes, thus overcoming some limitations of tramadol, including the potential for pharmacokinetic drug-drug interactions and interindividual variability due to genetic polymorphisms of cytochrome P450 enzymes. The toxicity profiles of tramadol and tapentadol are similar; however tapentadol is likely to result in less exposure to serotoninergic adverse effects (nausea, vomiting, hypoglycaemia) but cause more opioid adverse effects (constipation, respiratory depression, abuse) than tramadol. The safety of tapentadol in real-world conditions remains poorly documented, particularly in at-risk patient subgroups and also in the ability to assess the risk associated with its residual serotonergic activity (serotonin syndrome, seizures). Because of an earlier market introduction, more real-world safety data are available for tramadol, including data from at-risk patient subgroups. The level of evidence on the efficacy of both tramadol and tapentadol for the treatment of chronic pain is globally low. The trials published to date show overall that tapentadol does not provide a clinically significant analgesic improvement compared to existing treatments, for which the safety profile is much better known. In conclusion, tapentadol is not a first-line opioid but represents an additional analgesic in the therapeutic choices, which some patients may benefit from after careful examination of their clinical situation, co-morbidities and co-medications.
\end{abstract}

\section{Introduction}

Activation of opioid receptors, particularly the mu receptor, is one of the major therapeutic options for the treatment of moderate to severe pain. While the efficacy of opioids is well established in the management of acute nociceptive pain and chronic cancer pain $[1,2]$, the efficacy of opioids in the management of chronic non-cancer pain is less clear

Lucien Roulet

lucien.roulet@gmail.com

1 Division of Clinical Pharmacy, Hospital Pharmacy of Nord Vaudois and Broye Region, Rue d'Entremonts 11, 1400 Yverdon-les-Bains, Switzerland

2 Division of Clinical Pharmacology and Toxicology, Department of Anesthesiology, Pharmacology, Emergency Medicine and Intensive Care, Geneva University Hospitals and Geneva University, Geneva, Switzerland

3 Pain Clinic, Centre Jean-Violette, Geneva, Switzerland
$[3,4]$, and in any case goes hand in hand with significant iatrogenicity $[2,3]$.

From a pharmacological point of view, it is not possible to completely dissociate the analgesic activity and adverse effects of opioids to the extent that they are mediated by the same type of receptor [5]. Given the role of monoaminergic transmission in the descending pathways that inhibit spinal cord pain, noradrenaline and serotonin reuptake blockade are interesting and complementary mechanisms for potentiating opioid receptor activation [6].

According to their market authorisation holder, tramadol and then tapentadol were developed with this in mind. In both cases, the idea was to offer a molecule with complementary mechanisms of action to that of opioids, with the idea of achieving an analgesic efficacy comparable to that of a pure agonist while mitigating the adverse effects associated with opioid activation [7].

First marketed in Europe in 2011, tapentadol is being promoted as a mixed mechanism of action analgesic that 


\section{Key Points}

There is a lack of high-quality, head-to-head comparisons of tramadol and tapentadol, either with each other or with other opioids.

The level of evidence to support the use of tramadol and tapentadol in musculoskeletal or cancer-related chronic pain is low.

There is a low level of evidence to support the use of tramadol in neuropathic pain and tapentadol in diabetic peripheral neuropathy.

The efficacy and safety of tapentadol are reassuring in the geriatric population, but there is insufficient evidence to support its use in vulnerable elderly patients, as well as in patients with severe renal or hepatic impairment.

The adverse effect profile of tapentadol is potentially less serotonergic but more opioidergic than tramadol, with an advantage to tapentadol in terms of pharmacokinetic drug-drug interactions.

is effective across a broad spectrum of acute and chronic pain conditions, has a better safety profile than traditional strong opioids, and has the potential to overcome some of the limitations of tramadol [7-10].

We conducted a narrative review of the literature to compare the pharmacological efficacy and safety profiles of tapentadol and tramadol and to assess the clinical interest of tapentadol in adult patients. This narrative review was informed by a literature search of the Medline ${ }^{\circledR}$ database. Full-text articles were selected according to their relevance. In addition, any articles referenced in these papers that appeared relevant were retrieved and examined.

\section{Mechanisms of Action}

Tramadol and tapentadol are synthetic agonists that are reasonably selective for mu-opioid receptors, with an inhibitory effect on ascending pain pathways [7]. This effect is completed by a monoaminergic effect that enhances the descending inhibitory pain pathways [10], thereby decreasing the intensity of the ascending nociceptive stimuli.

Tramadol is marketed as a racemic mixture of two stereoisomers: $(+)$-tramadol preferentially inhibits the serotonin reuptake and (-)-tramadol preferentially inhibits the noradrenaline reuptake [9] (Table 1). Tramadol is eliminated via a complex metabolic cascade involving the cytochromes P450 (CYP) 2D6 and 3A4 [9]. Amongst its metabolites,
(+)-O-desmethyl-tramadol (the (+)-M1 metabolite) has approximately 700 -fold greater affinity than (+)-tramadol for the mu-opioid receptors [11]. Thus, when the parent drug is metabolised, the contribution of serotonin and noradrenaline reuptake inhibition decreases while the contribution of the mu-agonist effect increases, resulting in a complex pattern of pharmacological activity dependent on the rate and amount of active metabolites [7].

Unlike tramadol, the activity of tapentadol relies exclusively on its parent drug since it has no identified analgesically active metabolite. The parent drug has approximately a 50 -fold lower affinity in vitro for mu receptors than the (+)M1 metabolite of tramadol, but an equivalent mu-agonist analgesic effect based on in vivo data [11]. This apparent inconsistency could be explained by the different diffusion of these various active molecules in the central nervous system, or their ability to activate intracellular mechanisms after binding to the receptors [11].

Furthermore, tapentadol has an activity similar to (-)-tramadol on noradrenergic reuptake and is approximately five times less active than (+)-tramadol on serotonergic reuptake [11]. In vivo animal and human data confirmed that the noradrenergic and serotonergic activities of tramadol contribute to its analgesic effect $[12,13]$, unlike tapentadol where the noradrenergic activity is dominant over the serotonergic activity [7]. Overall, in vivo data show that tapentadol is approximately twice as potent as tramadol [11].

To summarize, tapentadol combines two specific synergistic mechanisms of analgesic action (mu-opioid receptor agonism and the inhibition of noradrenaline reuptake), whereas tramadol does not combine these two different mechanisms of action in the same molecule [14].

\section{Pharmacokinetics}

Key pharmacokinetic parameters for oral tramadol and tapentadol are compared in Table 2.

Despite good gastrointestinal absorption, the oral bioavailability of tapentadol is low, due to a large hepatic firstpass metabolism [18].

For immediate-release forms, the onset of action of tapentadol is more favourable than that of tramadol, which may not appear to be a drug of choice when it comes to rapidly relieving an acute painful condition. However, this must be balanced by the complexity of the pharmacokineticpharmacodynamic profile of tramadol, including significant differences in plasma and site-of-action concentrations of tramadol and pharmacodynamic synergies between the two enantiomers of tramadol and its active metabolites [19]. The duration of action of immediate-release forms of tapentadol is shorter than corresponding forms of tramadol. 
Table 1 In vitro evaluation of the binding affinity and functional activity of tramadol, tramadol enantiomers and metabolite M1, and tapentadol at human and rat MOR, SERT and NET (adapted from Raffa 2012 [11])

$\begin{array}{llllll}\begin{array}{l}\text { MOR Ki binding } \\ \text { affinity }(\mu \mathrm{M})\end{array} & \begin{array}{l}\text { MOR EC } \\ \text { GTP } \gamma \mathrm{S}(\mu \mathrm{M})\end{array} & \begin{array}{l}\text { SERT } K \text { i binding } \\ \text { affinity }(\mu \mathrm{M})\end{array} & \begin{array}{l}\text { SERT } K \text { i functional } \\ \text { uptake }(\mu \mathrm{M})\end{array} & \begin{array}{l}\text { NET } K \text { i binding } \\ \text { affinity }(\mu \mathrm{M})\end{array} & \begin{array}{l}\text { NET Ki func- } \\ \text { tional uptake } \\ (\mu \mathrm{M})\end{array}\end{array}$

\begin{tabular}{|c|c|c|c|c|c|c|}
\hline \multicolumn{7}{|l|}{ Tramadol } \\
\hline Racemic & $2.4^{\mathrm{a}}$ & Inactive $^{\mathrm{b}}$ & $1.19^{\mathrm{b}}$ & $0.99^{\mathrm{b}}$ & $14.6^{\mathrm{a}}$ & $0.78^{\mathrm{b}}$ \\
\hline$(+)$-Tramadol & $1.3^{\mathrm{b}}$ & NA & $0.87^{\mathrm{a}}$ & $0.53^{\mathrm{b}}$ & NA & $2.51^{b}$ \\
\hline (-)-Tramadol & $24.8^{\mathrm{b}}$ & NA & NA & $2.35^{\mathrm{b}}$ & NA & $0.43^{b}$ \\
\hline $\begin{array}{c}\text { (+)-O-desmethyl-trama- } \\
\text { dol (M1 metabolite) }\end{array}$ & $0.0034^{\mathrm{a}}$ & $0.86^{\mathrm{a}}$ & NA & $2.98^{\mathrm{b}}$ & NA & $14.4^{\mathrm{b}}$ \\
\hline Tapentadol & $0.16^{\mathrm{a}}$ & $0.67^{\mathrm{a}}$ & $5.28^{\mathrm{a}}$ & $2.37^{\mathrm{b}}$ & $8.8^{\mathrm{a}}$ & $0.48^{\mathrm{a}}$ \\
\hline
\end{tabular}

In contrast to its lower binding affinity, the functional activity of tapentadol on MOR is similar to that of the (+)-M1 metabolite of tramadol. In the same manner, the binding affinities of tapentadol for SERT and NET are similar, but tapentadol is nearly fivefold more potent in blocking NET than SERT. These differences highlight the importance of studying and comparing drugs based on their functional activity rather than on an indirect measure such as binding affinity (which does not take into account intrinsic activity, target access...) [11]

$\left.{ }^{35} S\right] G T P \gamma S$ radioactively labeled nonhydrolyzable GTP-analog, $E C_{50}$ half-maximal effective concentration, $M O R$ mu-opioid receptor, $N A$ not available, $N E T$ noradrenaline transporter, SERT serotonin transporter

${ }^{a}$ Measured in human

${ }^{\mathrm{b}}$ Measured in rat

Over $70 \%$ of tramadol is metabolised by CYPs and to a lesser extent by conjugation [20]. Phase I reactions are predominantly mediated by CYP3A4 (M2 metabolite formation pathway) and to a lesser extent by CYP2D6 (M1 metabolite formation pathway). Ultimately, $90 \%$ of tramadol and its 26 metabolites are eliminated by the kidneys, with $10-32 \%$ eliminated unchanged and 5-15\% eliminated as the M1 metabolite [19].

Tapentadol is metabolised primarily by glucuroconjugation (55\%) to the metabolite tapentadol-O-glucuronide [21], and secondarily by CYP2C9/2C19 (13\%) and 2D6 (2\%) to nortapentadol and 5-OH-tapentadol, respectively [9, 22]. It is $99 \%$ eliminated by renal excretion, mainly in a conjugated form [22].

\section{Equianalgesic Doses}

While animal data suggest an equianalgesic dose ratio from morphine to tapentadol of 1:2.5 [7], the sparse data from studies in patients with chronic pain of cancer or non-cancer origin suggest a ratio of about 1:3 irrespective of the direction of change [23, 24].

In comparison, the ratio of morphine to tramadol has been estimated to be between 1:6 and 1:10 for a parenteral administration and approximately 1:4 orally, due to the higher oral bioavailability of tramadol compared to morphine [25].

In practice, slightly different equianalgesic dose ratios are used for the oral route, to match marketed dosages (Table 3). In the case of an opioid rotation, these ratios also need to be carefully tailored taking into account the patient's

Table 2 Main pharmacokinetic parameters of oral forms of tramadol [15-17] and tapentadol [18] (after administration of a single dose)

\begin{tabular}{|c|c|c|c|c|c|}
\hline & Opioid & Onset of action ${ }^{\mathrm{a}}$ & Half-value duration ${ }^{b}$ & Oral bioavailability & Half-life \\
\hline \multirow[t]{2}{*}{ Immediate-release forms } & Tramadol & $\begin{array}{c}120 \min [60-180](\mathrm{M} 1: \\
150 \min [60-600])\end{array}$ & $6.3 \pm 1.6$ h (M1: $10.9 \pm 4.2$ h) & $68 \pm 13 \%$ & $\begin{array}{l}5.8 \pm 0.5 \mathrm{~h} \\
\quad(\mathrm{M} 1: 6.1 \pm 0.5 \mathrm{~h})\end{array}$ \\
\hline & Tapentadol & $60 \min [45-180]$ & $2.3 \pm 0.8 \mathrm{~h}$ & $32 \pm 3 \%$ & $4.9 \pm 0.7 \mathrm{~h}$ \\
\hline \multirow[t]{2}{*}{ Extended-release forms } & Tramadol & $4.9 \mathrm{~h}[4.4-5.4]$ & $10.4 \pm 2.7 \mathrm{~h}$ & & \\
\hline & Tapentadol & $5.0 \mathrm{~h}[1.0-7.0]$ & $11.7 \pm 3.3 \mathrm{~h}$ & & \\
\hline
\end{tabular}

Data are presented as mean \pm standard deviation, except for onset of action where they are presented as median [interval]

M1 O-desmethyl-tramadol (active metabolite of tramadol)

${ }^{\text {a }}$ Time to reach maximum concentration

${ }^{\mathrm{b}}$ Linear interpolation between the respective concentrations above and below $50 \% C_{\max }$ 
co-morbidities, co-medications, and the clinical circumstances that induced the rotation [26].

Ultimately, tapentadol is two to three times more potent than tramadol and two to three times less potent than morphine $[10,14]$. In Switzerland as in many other European countries, it is considered a strong opioid.

\section{Dosages in Multiple Settings}

\subsection{Usual Dosage in Adult Patients}

Usually recommended dosages of tramadol are in the range of 50-100 mg every $4-6 \mathrm{~h}$, or 100-200 mg every $12 \mathrm{~h}$ for extended-release forms, with a maximum daily dose of 400 $\mathrm{mg}$ (reserve doses included) [27].

Usually recommended doses of tapentadol are in the range of 50-100 mg every 4-6h, or 100-250 mg every $12 \mathrm{~h}$ for extended-release forms, with a maximum daily dose of $700 \mathrm{mg}$ on the first day followed by $600 \mathrm{mg}$ for immediaterelease forms, or $500 \mathrm{mg}$ for extended-release forms (reserve doses included) [18].

\subsection{Dosage in Patients with Renal Impairment}

Tramadol is not the opioid of choice for patients with severe renal impairment, as its elimination half-life is increased in this situation $[28,29]$. If tramadol administration is required, immediate-release tramadol should be selected in doses of $50 \mathrm{mg}$ and not exceeding $200 \mathrm{mg}$ per day for patients with a glomerular filtration rate (GFR) between 10 and $30 \mathrm{~mL} / \mathrm{min}$, and $100 \mathrm{mg}$ per day for patients with a GFR of less than 10 $\mathrm{mL} / \mathrm{min}$ or who are on dialysis [27, 30, 31].

To date, there are no accurate data on the use of tapentadol in renal impairment [10]. According to the summary of product characteristics (SmPC), no dosage adjustment is necessary in patients with mild to moderate renal impairment; however, tapentadol is not recommended in patients with severe renal impairment due to the lack of data in this context.

In practice, buprenorphine and fentanyl are both recommended opioids for use in patients with chronic kidney disease, including older patients or patients with severe renal impairment [29].

\subsection{Dosage in Patients with Hepatic Impairment}

An increase in the bioavailability and elimination half-life of tramadol is expected in cirrhosis due to decreased hepatic clearance [28]. In patients with hepatic impairment, a doubling of the dosing interval is therefore recommended to avoid tramadol accumulation [32].

Since tapentadol is primarily metabolized by glucuroconjugation, its use is not recommended in patients with severe hepatic impairment. In mild to moderate hepatic impairment, data are sparse, but by analogy with morphine, its use appears to be possible, as long as unit doses are halved and the dosing interval is doubled to account for its increased oral bioavailability (significant first-pass effect) [32].

In practice, morphine or hydromorphone at reduced doses appear to be the best oral opioid choices in patients with hepatic impairment [32].

\subsection{Dosage in Elderly Patients}

In patients aged 75 years or older, the bioavailability of the M1 metabolite (but not tramadol) increases by $35 \%$ compared to patients under 40 years of age, and its elimination half-life doubles. This accumulation is primarily due to a reduction in the renal clearance of the M1 metabolite [33]. For safety reasons, it is therefore recommended that dosing should be adapted to renal function and not exceed a maximum dose of $300 \mathrm{mg}$ per day from the age of 75 years on, or $200 \mathrm{mg}$ in co-morbid patients [27, 29].

According to the SmPC of tapentadol and to recent data $[34,35]$, no a priori dose adjustment is necessary in patients aged 65 years and older, in the absence of hepatic or renal impairment. In practice, a careful dose titration based on individual response is recommended in elderly patients treated with tapentadol [34].

\subsection{Dosage and Polymorphism of CYP2D6}

CYP2D6 is highly polymorphic. In poor metabolizers (PMs; $6-10 \%$ of the Caucasian population [36]), the opioid analgesic efficacy of tramadol is reduced. The plasma tramadol concentrations are approximately 20\% higher in PMs than those of normal metabolizers (NMs), and M1 metabolite concentrations are approximately $40 \%$ lower [37]. Conversely, in ultra-rapid metabolizers (UMs; $28 \%$ of North

Table 3 Usual equianalgesic doses between tramadol, tapentadol and morphine

\begin{tabular}{llll}
\hline Morphine IV & $1: 10$ & Tramadol IV & $10 \mathrm{mg}$ morphine IV $\approx 100 \mathrm{mg}$ tramadol IV \\
Morphine PO & $1: 5$ & Tramadol PO & $10 \mathrm{mg}$ morphine PO $\approx 50 \mathrm{mg}$ tramadol PO \\
Morphine PO & $1: 2.5$ & Tapentadol PO & $10 \mathrm{mg}$ morphine PO $\approx 25 \mathrm{mg}$ tapentadol PO \\
\hline
\end{tabular}

$I V$ intravenous, $P O$ oral 
Africans, Ethiopians and Arabs, and up to $10 \%$ of Caucasians [36]), the opioid effect and toxicity of tramadol rise due to the increase in the concentrations of the M1 metabolite [9]. In practice, in patients with known polymorphisms (PM or UM phenotype), it is recommended to avoid opioids that require bioactivation by CYP2D6 such as tramadol, codeine, oxycodone or hydrocodone [38].

CYP2D6 does not contribute significantly to the analgesic activity of tapentadol, which resides primarily in the parent drug, thereby significantly reducing the likelihood of interindividual CYP2D6-related variability in the analgesic response to tapentadol [9].

\section{Clinical Use}

Tramadol and tapentadol are officially indicated for the treatment of moderate to severe acute or chronic pain that cannot be adequately controlled by non-opioid analgesics. In the USA, tapentadol is also officially approved as an alternative for the treatment of diabetic peripheral neuropathy [10].

Clinical trials on the efficacy of tramadol and tapentadol are few and of limited quality, and independent and academic trials are scarce. In addition, some of these studies have been conducted under conditions far removed from clinical practice guidelines, for example, excluding the use of breakthrough doses or non-opioid co-analgesics [39].

\subsection{Acute Pain}

\subsubsection{Musculoskeletal Pain}

Since most cases of acute or subacute low back pain spontaneously improve over time, opioids are not recommended as a first-line treatment option: such pain should be managed with non-pharmacologic measures, or preferentially with non-steroidal anti-inflammatory drugs (NSAIDs) or muscle relaxants if pharmacologic treatment is required [40].

\subsubsection{Post-Operative Pain}

Several comparative clinical studies have demonstrated the analgesic efficacy of tramadol in the management of moderate to severe postoperative pain $[19,27]$. In this context, the analgesic efficacy of tramadol was comparable to that of morphine and NSAIDs. However, the level of evidence for the oral route is limited by the small number and size of published studies, the variety of the tested surgical settings, and the preponderance of parenteral use [27]. In practice, tramadol is an interesting postoperative oral analgesic, particularly when NSAIDs (cardiovascular, renal, digestive disorders) or opioids (respiratory depression) are contraindicated [19]. Its administration with non-opioid analgesics (paracetamol, NSAIDs) is pharmacologically relevant [19], and consistent with the multi-modal analgesia approach that is recommended for the management of postoperative pain [41]. Its combination with a strong opioid such as morphine should be avoided because it is infra-additive and leads to an increase in adverse effects [42]. Finally, the fact that it is not included in the list of narcotic drugs makes it easier to prescribe it when patients are discharged [27].

A systematic review of 13 randomized controlled trials concluded that tapentadol was not associated with a better control of moderate to severe acute pain compared to morphine, oxycodone or tramadol [43]. According to this analysis, most of the studies (11 of 13) had "some concerns" or "high risk" for bias. The authors also highlighted the heterogeneity of the indications covered by these studies, with an over-representation of minor interventions such as bunionectomy, making it difficult to extrapolate these results to major interventions. As the comparison between tramadol and tapentadol was based on only two small studies (160 patients in total), the authors noted that additional data were needed to confirm these results.

\subsection{Chronic Pain}

\subsubsection{Musculoskeletal Pain}

Tramadol monotherapy may provide low clinical improvement in moderate to severe chronic musculoskeletal pain compared to placebo [44-46], mainly in gonarthrosis and coxarthrosis [47]. However, data are lacking, especially those with an active comparator.

Tapentadol may provide low clinical improvement in moderate to severe chronic musculoskeletal pain compared with oxycodone [48-50]. In these randomized controlled trials, the study dropout rate was globally higher for lack of efficacy but lower for adverse effects in the tapentadol group than in the oxycodone group, with less gastrointestinal adverse effects in the tapentadol group [51].

In general, the long-term efficacy and safety of opioids in the management of chronic musculoskeletal pain remains poorly understood. Given the low expected benefit in relation to the risks involved (adverse effects, abuse, dependence), the use of opioids is not recommended as first-line treatment for these indications [40,52], even if tramadol could be indicated in carefully selected situations (e.g., contraindications to NSAIDs with no available surgical options) [53]. 


\subsubsection{Cancer Pain}

It is difficult to define the role of tramadol in the control of moderate to severe cancer pain [54]. Available data are of poor quality, due in part to the general lack of double-blind designs, the small number of participants and events, and a high risk of bias [55-57]. There is evidence (although of low quality) that tramadol is less effective than morphine for the relief of cancer pain [57].

According to a narrative review focusing on tapentadol for the palliation of cancer pain in adults [58], the research evidence from non-randomized, open-label or clinical practice studies suggests that tapentadol may be well tolerated when used in the ambulatory care setting, with few, typically mild adverse reactions, such as dizziness, loss of appetite, and nausea. To date, only three published randomized controlled trials have compared tapentadol to either placebo or an active control in patients with moderate to severe cancer pain, two of which were conducted in Japan and South Korea [59-61]. However, these studies were small and used heterogeneous designs, preventing the pooling of data for statistical analyses [58, 62]. Overall, a systematic review including these studies did not find any advantage of using tapentadol over morphine or oxycodone in terms of cancer pain relief or serious adverse events, with low-quality evidence [58, 62].

\subsubsection{Neuropathic Pain}

In most recommendations, traditional strong opioids are considered a third-line treatment for neuropathic pain because of their low efficacy and the risk of associated adverse effects and abuse. They should only be considered on a case-by-case basis if all other lines of treatment fail [63]. Tramadol and tapentadol, which differ from traditional opioids due to their mixed mode of action with a monoaminergic component, have been presented as active in a wide range of painful conditions, including neuropathic pain [11]. In the USA, tapentadol was approved by the Food and Drug Administration (FDA) for the treatment of painful diabetic peripheral neuropathy in 2012 [64].

Few randomized controlled trials have compared tramadol to either placebo or an active control in patients with moderate to severe neuropathic pain, including peripheral diabetic neuropathy [65], postherpetic neuralgia [66], polyneuropathy [67] and spinal cord injury [68]. Overall, the evidence to support the use of tramadol in this setting is low as the available studies included a wide variety of neuropathic pain, were of very short duration, had a high risk of bias and were small, which could lead to an overestimation of the benefits of tramadol [69]. Despite these limitations, tramadol is recommended as second- or third-line therapy in international guidelines [63, 70-72].
For tapentadol, only two of the three randomized controlled trials conducted to date in diabetic peripheral neuropathy have concluded that tapentadol is superior to placebo $[64,72]$. On the basis of the available data, its efficacy in this indication was considered inferior to that of tramadol, and probably overestimated by the choice of an enriched study design, which led to the exclusion of opioid non-responders $[64,73]$. Finally, there are no comparative trials between tapentadol and reference treatments in this indication. Furthermore, no studies have evaluated the use of tapentadol for other neuropathic conditions.

In conclusion, there is a low level of evidence to support the use of tramadol in neuropathic pain and tapentadol in diabetic peripheral neuropathy. In practice, they may be of practical value as last-line adjunctive treatment, in combination with first-line treatments where these are insufficient, and provided that drugs that also have a serotonergic activity are avoided to prevent cumulative adverse effects (see below) [63, 70-72].

\subsubsection{Chronic Pain of Non-Cancer Origin in Elderly Patients}

Despite accounting for a large proportion of patients who suffer from and are treated for chronic pain, elderly patients are often excluded from clinical trials assessing analgesics.

Although tramadol is frequently used in elderly patients with chronic pain, data for this subset of the population are scarce [74, 75]. The level of evidence is low, with a high proportion of elderly patients discontinuing tramadol use because of adverse effects [75]. In addition, we found no active-controlled trials.

In recent years, elderly patients were included in several studies of tapentadol [34, 35, 76-78], some of which were active-controlled trials [77]. Durations of follow-up were short (maximum of 4 months), and a high proportion of elderly patients discontinued tapentadol use because of adverse effects [34, 77].

Overall, tapentadol is better documented in the literature than tramadol for the management of chronic pain of noncancer origin in elderly patients. Although the results on the efficacy and safety of tapentadol in this population are reassuring, there is still insufficient evidence to support its use in vulnerable elderly patients [79].

\section{Adverse Effect Profiles}

For analgesics with a mixed mechanism of action (such as tramadol and tapentadol), some authors have proposed the concept of "mu load" to quantify the percentage contribution of the mu-opioid component to their adverse effect profile compared to that of a pure mu agonist at equianalgesic doses 
$[14,80]$. Following this approach, the mu load of tapentadol would be less than $40 \%$ compared to pure mu agonists, and this reduced mu load could result in a more favourable adverse effect profile compared to that of traditional strong opioids. This concept also suggests the reconsideration of the rescue of the noradrenergic system as a key mechanism to support the application of analgesics with a mixed mechanism of action for managing different forms of mixed pain (e.g., inflammatory and neuropathic). Apart from this interesting theory, it is important to keep in mind that traditional strong opioids also interact with receptors other than the mu receptor (e.g., delta and kappa opioid receptors, N-methyl$\mathrm{D}$-aspartate receptor), and differ from each other in their interactions with these receptors $[81,82]$.

In animal studies, brain, lung, heart, kidney and liver damage have been associated with exposure to particularly high and toxic doses of tramadol and tapentadol [83, 84]. In humans, the adverse effect profile of tramadol and tapentadol is very similar to that of opioids. Nausea, vomiting, dizziness, drowsiness, fatigue, hypersedation and dry mouth are among the most commonly reported adverse effects $[10$, $85,86]$.

The frequency of adverse effects reported with tramadol and tapentadol is highly variable across studies, reflecting the wide range of indications, doses and populations studied as well as the methodologies and sources of information used in the studies. In addition, as tapentadol has been marketed much more recently than tramadol, the number of studies of adverse effects is more limited, making comparisons with tramadol difficult [10]. Based on the information discussed in the following paragraphs, tapentadol appears to have a higher risk of constipation, respiratory depression, abuse and complications due to overdose, but a lower risk of nausea/vomiting and hypoglycaemia than tramadol. These trends need to viewed with caution because of the lack of sufficient experience with tapentadol and direct comparison of the two molecules. In addition, the available data do not allow conclusions to be drawn about the risk of seizures and serotonin syndrome.

\subsection{Nausea and Vomiting}

Tramadol, like all opioids, is frequently associated with nausea and vomiting [85]. The frequency of these adverse effects is time and dose dependent [87], and can be reduced by gradual introduction, for example with dose increments of $50 \mathrm{mg}$ every 4 days [88]. The frequency of these adverse effects appears to be at least equivalent to-and even higher than - that reported with codeine, a difference that may be explained by the combined action of tramadol on opioid, dopaminergic and serotonergic receptors in the chemoreceptor trigger zone of the postrema area [89].
Similarly, nausea and vomiting are among the most commonly reported adverse effects with tapentadol [86]. In clinical trials, the incidence of nausea and vomiting was significantly lower with tapentadol than with oxycodone [10].

In the absence of direct comparison, it is not possible to assess whether tapentadol has a significant advantage over tramadol in terms of nausea and vomiting. The clinical relevance of such a benefit would be weak as these opioid adverse effects usually resolve rapidly after the introduction of the treatment and can be easily controlled by the addition of an antiemetic [79].

\subsection{Constipation}

Constipation is a very common adverse effect of opioids and is a major issue in the treatment of chronic pain, particularly in vulnerable elderly patients. In most cases, no tolerance is observed over time, which means that prophylactic laxative treatment is required in most patients for the duration of opioid treatment [79].

Tramadol is associated with a low incidence of constipation $[85,90]$. One study showed minor interference of tramadol with gastrointestinal motility compared with placebo, but its significance is limited by its sample size (only nine healthy volunteers) [91].

In clinical trials, the incidence of constipation and the rate of study dropout for constipation were significantly lower with tapentadol than with oxycodone [92]. This comparison is limited and biased by the fact that these studies did not take into account the concomitant use of laxatives [39]. Furthermore, the strong recommendation to prescribe a laxative at the same time as long-term opioid treatment puts the clinical relevance of this benefit into perspective [79].

In practice, it does not appear to be useful to prescribe a standard laxative for patients treated with tramadol who do not have a history of constipation. Tapentadol, on the other hand, should be used with the same caution as strong opioids, and its value in patients for whom adequate laxative treatment is not sufficient to adequately regulate transit when treated with opioids has yet to be demonstrated.

\subsection{Respiratory Depression}

Respiratory depression is frequently observed with opioids because they reduce the sensitivity of the respiratory centres to carbon dioxide, a phenomenon that is partially compensated for by the fact that pain is a stimulant for breathing [28].

Clinical experience shows a weak respiratory depressant effect of tramadol in the intraoperative period [85], a very particular context in which breathing is the result of a balance between stimulation due to pain and stress and 
depression resulting from the direct effect of analgesics and anaesthetics [93]. However, in a study in healthy volunteers, a single $100 \mathrm{mg}$ dose of immediate-release tramadol reduced mean ventilatory sensitivity to carbon dioxide by about 30\% [93]. This risk has been confirmed by spontaneously reported cases since tramadol was first marketed [90].

A study conducted in healthy volunteers showed that tapentadol also had a respiratory depressant effect [94]. In this study, a single dose of $100 \mathrm{mg}$ immediate-release tapentadol induced significantly less respiratory depression than an equianalgesic dose of $20 \mathrm{mg}$ oxycodone. The authors suggest that the noradrenergic stimulatory effects of tapentadol may partially compensate for the respiratory depression induced by its opioid activity. However, as for tramadol, this risk has been confirmed by cases reported in clinical trials with tapentadol [86].

Respiratory depression is therefore a possible but rare adverse effect of tramadol and tapentadol, mainly in patients with other risk factors or exposed to supra-therapeutic doses $[85,86,95]$. In practice, only tapentadol is contraindicated in acute asthma or severe respiratory failure.

\subsection{Serotonin Syndrome}

Serotonin syndrome is a serious but difficult to diagnose adverse effect, particularly in the case of concomitant opioid treatment, since some of these symptoms may be confused with those of an opioid overdose, or, on the contrary, those of withdrawal (following, e.g., the administration of naloxone) [86].

Cases of serotonin syndrome have been reported with tramadol, most often in patients exposed to other drugs with serotonergic properties, such as selective serotonin reuptake inhibitors (SSRIs), serotonin and noradrenaline reuptake inhibitors (SNRIs), tricyclic antidepressants (TCAs) and monoamine oxidase inhibitors (MAOIs), including linezolid and isoniazid [10, 90, 96]. However, a few cases of deliberate intoxication show that tramadol alone can induce serotonin syndrome in case of massive overdose [90].

Tapentadol has a lower serotonergic effect, theoretically reducing its risk of inducing serotonin syndrome $[9,86]$. In an analysis of global pharmacovigilance data in 2016, tapentadol was the second most frequently suspected opioid in reported cases of serotonin syndrome, after tramadol [97]. The earlier availability of tramadol and its widespread use may account for this difference [97]. Furthermore, clinical trials of tapentadol often excluded patients taking other serotonergic drugs (except for SSRIs that had been at a stable dose given for at least 1 month) and were not designed to reliably detect an adverse effect as complex as serotonin syndrome [98].
In practice, tramadol, and to a lesser extent tapentadol, should be used with caution and at reduced doses in patients treated with SSRI/SNRI/TCA antidepressants, and are contraindicated in patients treated with MAOIs (including linezolid and isoniazid) [99].

\subsection{Convulsions}

Convulsions are a known but very rare adverse effect of pure opioid agonists, probably due to a lowering of the seizure threshold by inhibiting the intracerebral release of gammaaminobutyric acid [86].

Convulsions are among the most common serious neurological adverse effects reported with tramadol $[85,90]$. This risk is increased in patients with a history of convulsions or exposure to other substances that lower the seizure threshold, including psychotropic drugs [85].

Patients with epilepsy were excluded from clinical trials with tapentadol [86]. Data collected since tapentadol has been marketed suggest that the frequency of convulsions under tapentadol treatment is low, including in patients with risk factors for convulsions, but these results should be interpreted with caution given the small number of cases included in these analyses [86]. However, a press release from the UK Medicines and Healthcare products Regulatory Agency (MHRA) issued a warning of the risk of epileptic seizures associated with tapentadol following the analysis of European pharmacovigilance data [100]. In almost half of the reported cases, tapentadol was associated with at least one other drug known to lower the seizure threshold, including SSRIs, SNRIs, TCAs and antipsychotics.

In practice, tramadol and tapentadol should be used with caution in patients with a history of seizures or concomitant administration of drugs that lower the seizure threshold. They are both contraindicated in patients with poorly controlled epilepsy.

\subsection{Hypoglycaemia}

An analysis of hypoglycaemia cases recorded in two pharmacovigilance databases between 1967 and 2018 supports the hypothesis of a class effect with opioids, which could be dose-dependent, with diabetic patients and women being more at risk [101]. In this study, tramadol was the opioid for which the most cases of hypoglycaemia were reported. Tapentadol was not included in the analysis.

An analysis of a US pharmacovigilance database over the same time period but using a different methodology also concluded that tramadol is the opioid most likely to be associated with hypoglycaemia and identified a few cases related to tapentadol [102]. This study did not find a trend 
towards increased risk in diabetic patients, unlike the previous one. These apparently contradictory results could reveal a classification bias in some diabetic patients, where cases of hypoglycaemia attributed to an opioid are explained by a misuse of the anti-diabetic treatment favoured by cognitive disorders frequently induced by opioids [103].

To date, the pathophysiological mechanisms at the origin of opioid-induced hypoglycaemia remain poorly understood and debated. They may result from an increase in glucose central utilisation as a result of stimulation of mu-opioid receptors and some serotonergic receptors, which may account for the higher proportion of cases associated with tramadol and methadone [101, 102].

In practice, it seems sensible to inform diabetic patients, particularly women, of the increased risk of hypoglycaemia they may experience during opioid treatment (including tapentadol), and particularly with tramadol.

\subsection{Cardiovascular Effects}

Orthostatic hypotension is a known adverse effect of tramadol, occurring more frequently after parenteral administration than other routes and due to peripheral venous vasodilation [85]. Rhythm disturbances (tachycardia, bradycardia, atrial fibrillation) have also been reported [90]. In healthy volunteers, tramadol did not induce a significant QT-interval prolongation at doses up to $600 \mathrm{mg}$ per day for 3 days [104]. Cardiac arrest has exceptionally been reported after overdoses in patients who may have had other risk factors (UM phenotype for CYP2D6, genetic predisposition) [90, 104].

According to a post hoc analysis of three clinical trials, tapentadol treatment was not associated with significant changes in heart rate or blood pressure in patients known to have hypertension and treated for 2 weeks with a dose between 200 and $500 \mathrm{mg}$ per day [105]. These results are reassuring with regard to the overall cardiovascular safety of tapentadol, although they should not obscure the fact that its noradrenergic activity can induce serious tachycardia in isolated cases [106]. Furthermore, tapentadol did not induce significant prolongation of the QT interval in healthy volunteers at doses of up to $600 \mathrm{mg}$ per day for 2 days [107].

In practice, both tramadol and tapentadol have good cardiovascular safety profiles at therapeutic doses and may therefore be an interesting alternative to NSAIDs in highrisk cardiovascular patients with mild to moderate pain. Serious cardiovascular effects may be observed, but mainly in the case of overdose and therefore in situations where it is difficult to distinguish from the symptoms induced by a serotonin syndrome.

\subsection{Risk of Dependency and Abuse}

The risk of dependency and abuse with tramadol has long been considered to be lower than that of strong opioids [27, 85], so much so that extended-release forms of tramadol have even been proposed, in doses up to $600 \mathrm{mg}$ per day, as a replacement therapy for opioid dependence [108]. However, a recent US study unexpectedly found that tramadol was associated with as much or more risk of switching from acute to prolonged use as other short-acting opioids, a finding that has since been confirmed in patients treated for acute pain after elective surgery [109]. Although it is difficult to extrapolate these results to the European level, given the health crisis in the USA in recent years over the misuse of opioids [10], the problem seems to be confirmed in other countries. For example, global consumption of tramadol increased by $42 \%$ between 2006 and 2012 and, in response to a parallel increase in abuse and relative deaths, many countries-including Sweden, Australia, Brazil, Japan, China, the UK and the USA - have placed tramadol under national control [10]. In addition, withdrawal syndromes have also been reported with long-term ( $>1$ month) treatment [90].

The risk of diversion for non-medical purposes was taken into account in the development of tapentadol by marketing extended-release tablets designed to be difficult to crush and solubilise. However, cases of recreational use by chewing or inhaling have been reported with immediate-release tablets [110], as well as abuse by injection of crushed immediaterelease tablets, some of which have led to death by cardiorespiratory arrest [111]. In a study using data from a US prescription drug-monitoring system, the abuse potential of tapentadol was found to be significantly higher than that of tramadol, but equivalent to that of hydrocodone and lower than that of other strong opioids after adjustment for prescription volume [112]. This finding has recently been confirmed by a review of US poison, drug diversion and addiction treatment centres [113]. Withdrawal syndromes have also been reported in patients exposed to supra-therapeutic doses [86].

Unlike tramadol, tapentadol therefore appears to have a similar abuse risk to strong opioids, which has led Switzerland and other European countries to classify it as a narcotic drug. In practice, in patients receiving tramadol or tapentadol for the treatment of moderate to severe postoperative pain, the risk of abuse is likely to be limited if the administration is mainly hospital-based and of short duration [27]. On the other hand, their use on an outpatient basis, especially in the long term, requires the same caution as with strong opioids. 


\subsection{Intoxications}

A study based on data from the American Association of Poison Control Centres (AAPCC) compared the reported poisonings by ingestion of tramadol and tapentadol in the USA between 2009 and 2011 [95]. Overall, tapentadol was more frequently associated with severe poisoning (as defined by the AAPCC), with a higher risk of respiratory depression, coma, confusion and hallucinations. Tramadol intoxication was associated with a higher risk of convulsions and vomiting. These results should be interpreted with caution given the small number of cases included over this period for tapentadol ( $n=217)$. It is interesting to note that a significant number of overdose cases may be the result of insufficient analgesia, leading to an increase in doses beyond the recommended limits [86].

In both cases, naloxone is used to counteract the toxic opioid effects of tramadol and tapentadol. However, this antidote is of no use in counteracting the toxic effects associated with their monoaminergic component, such as convulsions.

\section{Pharmacokinetic Drug-Drug Interactions}

The bioactivation of tramadol by CYP2D6 is an important source of variability due to drug interaction. The analgesic efficacy of tramadol can be significantly reduced by CYP2D6 inhibitors, such as some SSRIs or terbinafine [114, 115].

In patients with functional CYP2D6, available data show that the use of a potent CYP3A4 inhibitor with tramadol justifies dose reduction and monitoring for signs of overdose [116]. On the other hand, potent CYP3A4 inducers have the potential to significantly reduce the analgesic efficacy of tramadol by reducing not only plasma levels of tramadol but also those of its metabolite M1 as a result of the shift from the CYP2D6 pathway (leading to M1) to the CYP3A4 pathway (leading to M2) [117]. In practice, great caution is recommended with CYP3A4 inhibitors and inducers as well as with CYP2D6 inhibitors [20].

Conversely, the potential for drug interactions is theoretically lower with tapentadol as it is not extensively metabolised by the CYP system [9]. It is mainly metabolised by the uridine-diphosphate-glucuronosyltransferases (UGT) $1 \mathrm{~A} 9$ and 2B7 [22]. UGTs are high-capacity enzymes and have no known potent inhibitors, but they are genetically polymorphic, so that an influence on their activity cannot be completely ruled out $[9,22]$.

\section{Cost Effectiveness}

Pharmacoeconomic studies have compared tapentadol with other strong opioids, but not with tramadol. These studies concluded that tapentadol is cost effective compared with oxycodone alone [118-122] or in combination with naloxone [123], but not with morphine or transdermal fentanyl [119]. However, these data should be treated with caution as they all come from studies carried out directly [118-122] or indirectly [123] by companies marketing tapentadol. Methodological limitations also make their interpretation difficult, such as the lack of direct comparison between tapentadol and its comparator, or the diversity of models used from one study to another $[124,125]$.

\section{Availability and Prescription Modalities}

The availability of a drug and the way in which it is prescribed are particularly important factors in studying its use and identifying possible misuse or abuse in the population.

In 2020, tramadol was available in 40 countries around the world (including Australia, Canada, China, India, Japan, Russia, the USA), including 18 European countries (including France, Germany, Switzerland and the UK). Tapentadol was available in 28 countries around the world (including Australia, Canada, Japan, Russia, the USA, but not China or India), including 18 European countries (including Germany, Switzerland and the UK, but not France) [126].

Comparison of drug-prescription modalities between countries is difficult due to the diversity of regulatory systems in force. A recent review of the conditions for prescribing analgesics in Europe illustrates the wide variation in the restrictions imposed from one country to another for the same analgesic [127]. The data also show that the prescribing conditions for tapentadol in Europe are generally more restrictive than those for tramadol (Fig. 1).

\section{Conclusion}

Tapentadol might be of interest compared to tramadol, but many questions remain open. While tapentadol may overcome some of the limitations of tramadol, such as the likelihood of drug interaction or interindividual variability due to genetic polymorphisms in CYP450, its "efficacy in a wide range of acute and chronic pain conditions" or its "better tolerability profile than traditional strong opioids" are assertions that have yet to be demonstrated in well-conducted studies (Table 4). 
Fig. 1 Conditions of prescription and delivery of tramadol (a) and tapentadol (b) in Europe (situation in 2015). Reproduced with permission from Palmaro et al. [127] a
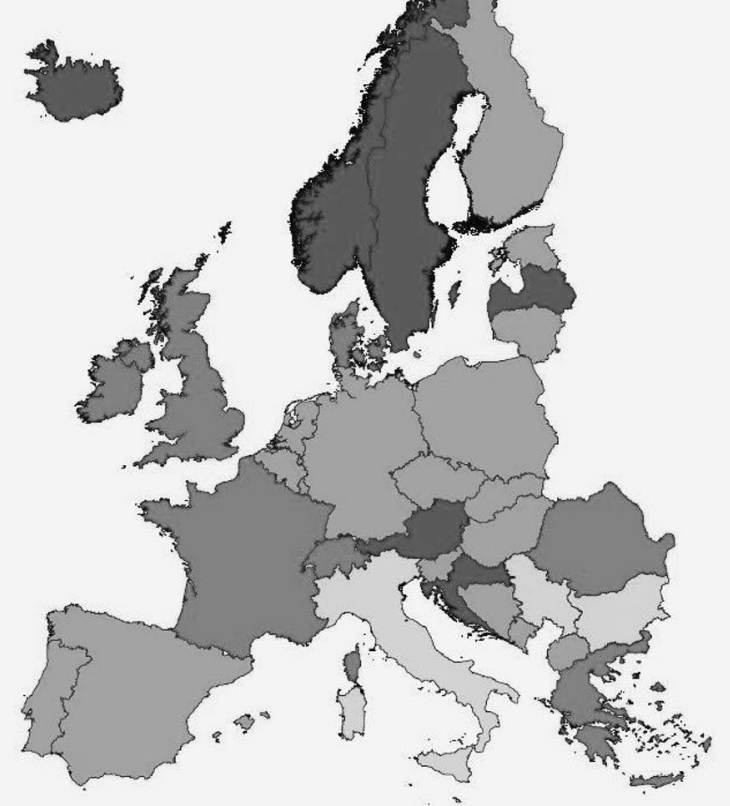

b

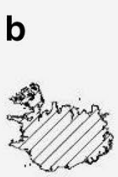

.

sint
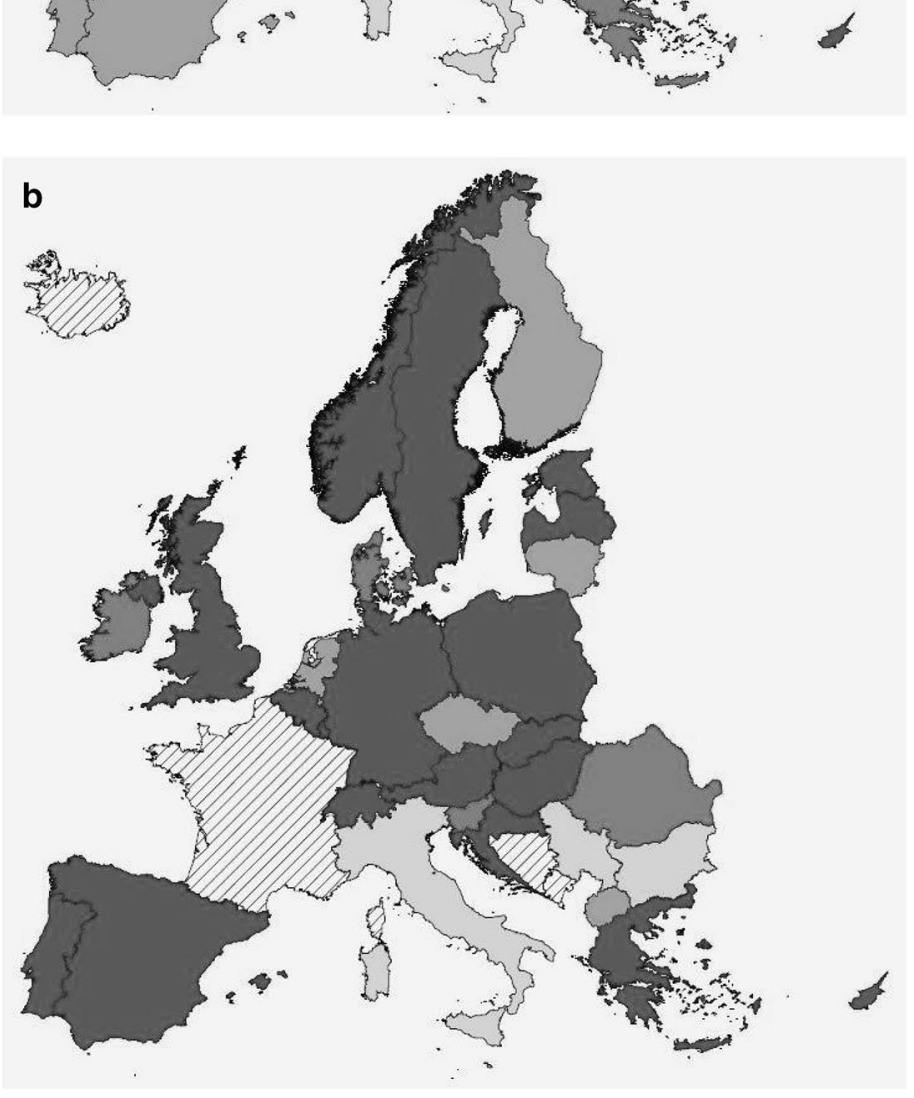

Unavailable

Authorized (no additional information available)

On medical prescription

On restricted medical prescription

Narcotic drug 
Table 4 Comparison of oral forms of tramadol and tapentadol

\begin{tabular}{|c|c|c|}
\hline & Tramadol & Tapentadol \\
\hline \multicolumn{3}{|l|}{ Handling } \\
\hline Available galenic forms & $\begin{array}{l}\text { Oral solution } \\
\text { IR and ER tablets }\end{array}$ & $\begin{array}{l}\text { Oral solution } \\
\text { IR and ER tablets }\end{array}$ \\
\hline Alternative galenic forms & Yes (rectal, injectable) & No \\
\hline Frequency of administration of IR forms & Every $12 \mathrm{~h}$ & Every $12 \mathrm{~h}$ \\
\hline Drug scheduling & $\begin{array}{l}\text { USA: DEA schedule IV } \\
\text { EU: not on the list of narcotic drugs }\end{array}$ & $\begin{array}{l}\text { USA: DEA schedule II } \\
\text { EU: on the list of narcotic drugs }\end{array}$ \\
\hline \multicolumn{3}{|l|}{ Efficacy } \\
\hline Onset of action of IR forms & Approx. $2 \mathrm{~h}$ & Approx. $1 \mathrm{~h}$ \\
\hline Postoperative pain & Probably as effective as morphine & Probably as effective as morphine \\
\hline Cancer pain & Could be less effective than morphine & Could be as effective as morphine \\
\hline Diabetic peripheral neuropathy & Second- or third-line treatment & Last line of treatment \\
\hline Other neuropathic pain & Second- or third-line treatment & No data \\
\hline \multicolumn{3}{|l|}{ Security } \\
\hline Potential for adverse effects & $\begin{array}{l}\text { Potentially higher risk of nausea/vomiting and } \\
\text { hypoglycaemia }\end{array}$ & $\begin{array}{l}\text { Potentially higher risk of constipation, respiratory } \\
\text { depression, abuse and complications in case of } \\
\text { intoxication }\end{array}$ \\
\hline Use in severe renal impairment & To be avoided, possible with dosage adjustment & $\begin{array}{l}\text { Not recommended due to insufficient clinical } \\
\text { experience }\end{array}$ \\
\hline Use in severe hepatic impairment & To be avoided, possible with dosage adjustment & $\begin{array}{l}\text { Not recommended due to insufficient clinical } \\
\text { experience }\end{array}$ \\
\hline Use in the elderly & $\begin{array}{l}\text { Possible with dosage adjustment according to } \\
\text { clinical experience }\end{array}$ & $\begin{array}{l}\text { Possible without dosage adjustment, but with } \\
\text { careful dose titration }\end{array}$ \\
\hline Potential for PK interaction ${ }^{\#}$ & High (via CYP 3A4 and 2D6) & Low \\
\hline Potential for interindividual variability & High (genetic polymorphism of CYP2D6) & Moderate (low oral bioavailability) \\
\hline \multicolumn{3}{|l|}{ Cost effectiveness } \\
\hline Cost of daily treatment ${ }^{\$}$ & Tramal $^{\circledR}$ ER $100 \mathrm{mg} 2$ tablets: $1.05 \mathrm{CHF}$ & Palexia ${ }^{\circledR}$ ER $50 \mathrm{mg} 2$ tablets: $2.35 \mathrm{CHF}$ \\
\hline
\end{tabular}

$C H F$ Swiss francs, DEA United States Drug Enforcement Administration, ER extended-release, EU European countries, $I R$ immediate release, $P K$ pharmacokinetic, USA United States of America

*According to 2020 data

\#As tramadol is bioactivated through CYP2D6, this also influences its effectiveness

${ }^{\$}$ Equianalgesic doses, Swiss public prices on 15 December 2020

The adverse effect profiles of tramadol and tapentadol seem similar depending on the clinical situation, with tapentadol potentially exposing less to serotonergic effects but more to opioid effects than tramadol. Nevertheless, the available literature on the safety of tapentadol in real-life conditions remains incomplete, particularly in subgroups of patients at risk. There is also a lack of data to assess the risk of serotonin syndrome and convulsions associated with its residual serotonergic activity.

Finally, the level of evidence on the efficacy of both tramadol and tapentadol for the treatment of chronic pain is globally low. The trials published to date in adults generally show that tapentadol does not provide a clinically superior analgesic improvement compared with treatments that have been on the market for longer, which are often cheaper and have a better documented safety profile.
Tapentadol therefore represents an additional analgesic in the therapeutic arsenal available to prescribers, which some patients may benefit from after careful consideration of their clinical situation, co-morbidities and co-medications. However, when a first-line opioid is chosen because non-opioid analgesics are not or are no longer effective, the Socratic adage should prevail: "better the devil you know than the devil you don't".

\section{Declarations}

Funding Not applicable.

Conflicts of interest/Competing interests: The authors declare that they have no conflicts of interest.

Ethics approval: Not applicable.

Consent to participate Not applicable. 
Consent for publication Not applicable.

Availability of data and material Not applicable.

Code availability Not applicable.

Authors' contributions Conceptualisation: LR, JD, VP; Literature search and data analysis, Writing - original draft preparation: LR; Writing-English editing: VR; Writing—critical review: VR, JD, Valérie Piguet; Supervision: VP.

Open Access This article is licensed under a Creative Commons Attribution-NonCommercial 4.0 International License, which permits any non-commercial use, sharing, adaptation, distribution and reproduction in any medium or format, as long as you give appropriate credit to the original author(s) and the source, provide a link to the Creative Commons licence, and indicate if changes were made. The images or other third party material in this article are included in the article's Creative Commons licence, unless indicated otherwise in a credit line to the material. If material is not included in the article's Creative Commons licence and your intended use is not permitted by statutory regulation or exceeds the permitted use, you will need to obtain permission directly from the copyright holder. To view a copy of this licence, visit http://creativecommons.org/licenses/by-nc/4.0/.

\section{References}

1. MacKenzie M, Zed PJ, Ensom MHH. Opioid pharmacokineticspharmacodynamics: clinical implications in acute pain management in trauma. Ann Pharmacother. 2016;50(3):209-18.

2. Wiffen PJ, Wee B, Derry S, Bell RF, Moore RA. Opioids for cancer pain - an overview of Cochrane reviews. Cochrane Database Syst Rev. 2017;7:CD012592.

3. Busse JW, Wang L, Kamaleldin M, Craigie S, Riva JJ, Montoya $\mathrm{L}$, et al. Opioids for chronic noncancer pain: a systematic review and meta-analysis. JAMA. 2018;320(23):2448-60.

4. Sommer C, Klose P, Welsch P, Petzke F, Häuser W. Opioids for chronic non-cancer neuropathic pain. An updated systematic review and meta-analysis of efficacy, tolerability and safety in randomized placebo-controlled studies of at least 4 weeks duration. Eur J Pain. 2020;24(1):3-18.

5. Matthes HW, Maldonado R, Simonin F, Valverde O, Slowe S, Kitchen I, et al. Loss of morphine-induced analgesia, reward effect and withdrawal symptoms in mice lacking the mu-opioidreceptor gene. Nature. 1996;383(6603):819-23.

6. Verdu B, Decosterd I, Buclin T, Stiefel F, Berney A. Antidepressants for the treatment of chronic pain. Drugs. 2008;68(18):2611-32.

7. Tzschentke TM, Christoph T, Kögel B, Schiene K, Hennies H-H, Englberger W, et al. (-)-(1R,2R)-3-(3-dimethylamino-1-ethyl2-methyl-propyl)-phenol hydrochloride (tapentadol $\mathrm{HCl}$ ): a novel mu-opioid receptor agonist/norepinephrine reuptake inhibitor with broad-spectrum analgesic properties. J Pharmacol Exp Ther. 2007;323(1):265-76.

8. Raffa RB, Haidery M, Huang H-M, Kalladeen K, Lockstein DE, Ono H, et al. The clinical analgesic efficacy of buprenorphine. J Clin Pharm Ther. 2014;39(6):577-83.

9. Barbosa J, Faria J, Queirós O, Moreira R, Carvalho F, DinisOliveira RJ. Comparative metabolism of tramadol and tapentadol: a toxicological perspective. Drug Metab Rev. 2016;48(4):577-92.
10. Faria J, Barbosa J, Moreira R, Queirós O, Carvalho F, DinisOliveira RJ. Comparative pharmacology and toxicology of tramadol and tapentadol. Eur J Pain. 2018;22(5):827-44.

11. Raffa RB, Buschmann H, Christoph T, Eichenbaum G, Englberger W, Flores CM, et al. Mechanistic and functional differentiation of tapentadol and tramadol. Expert Opin Pharmacother. 2012;13(10):1437-49.

12. Raffa RB, Friderichs E, Reimann W, Shank RP, Codd EE, Vaught JL. Opioid and nonopioid components independently contribute to the mechanism of action of tramadol, an « atypical» opioid analgesic. J Pharmacol Exp Ther. 1992;260(1):275-85.

13. Desmeules JA, Piguet V, Collart L, Dayer P. Contribution of monoaminergic modulation to the analgesic effect of tramadol. Br J Clin Pharmacol. 1996;41(1):7-12.

14. Raffa RB, Elling C, Tzschentke TM. Does «strong analgesic » equal «strong opioid »? tapentadol and the concept of « $\mu$-Load ». Adv Ther. 2018;35(10):1471-84.

15. Malonne H, Sonet B, Streel B, Lebrun S, De Niet S, Sereno A, et al. Pharmacokinetic evaluation of a new oral sustained release dosage form of tramadol. Br J Clin Pharmacol. 2004;57(3):270-8.

16. Cnota PJ, Nowak H, Tagarro I, Erb K, Schürer M, Schulz H-U, et al. Tramadol SR formulations : pharmacokinetic comparison of a multiple-units dose (Capsule) versus a single-unit dose (Tablet). Clin Drug Investig. 2005;25(7):435-43.

17. Fliegert F, Kurth B, Göhler K. The effects of tramadol on static and dynamic pupillometry in healthy subjects-the relationship between pharmacodynamics, pharmacokinetics and CYP2D6 metaboliser status. Eur J Clin Pharmacol. 2005;61(4):257-66.

18. Göhler K, Brett M, Smit JW, Rengelshausen J, Terlinden R. Comparative pharmacokinetics and bioavailability of tapentadol following oral administration of immediate- and prolonged-release formulations. Int J Clin Pharmacol Ther. 2013;51(4):338-48.

19. Grond S, Sablotzki A. Clinical pharmacology of tramadol. Clin Pharmacokinet. 2004;43(13):879-923.

20. Overholser BR, Foster DR. Opioid pharmacokinetic drug-drug interactions. Am J Manag Care. 2011;17(Suppl 11):S276-287.

21. Terlinden R, Kogel BY, Englberger W, Tzschentke TM. In vitro and in vivo characterization of tapentadol metabolites. Methods Find Exp Clin Pharmacol. 2010;32(1):31-8.

22. Terlinden R, Ossig J, Fliegert F, Lange C, Göhler K. Absorption, metabolism, and excretion of 14C-labeled tapentadol $\mathrm{HCl}$ in healthy male subjects. Eur J Drug Metab Pharmacokinet. 2007;32(3):163-9.

23. Mercadante S, Porzio G, Aielli F, Adile C, Verna L, Ficorella C, et al. Opioid switching from and to tapentadol extended release in cancer patients: conversion ratio with other opioids. Curr Med Res Opin. 2013;29(6):661-6.

24. Gálvez R, Schäfer M, Hans G, Falke D, Steigerwald I. Tapentadol prolonged release versus strong opioids for severe, chronic low back pain: results of an open-label, phase $3 \mathrm{~b}$ study. Adv Ther. 2013;30(3):229-59.

25. Wilder-Smith CH, Schimke J, Osterwalder B, Senn HJ. Oral tramadol, a mu-opioid agonist and monoamine reuptakeblocker, and morphine for strong cancer-related pain. Ann Oncol. 1994;5(2):141-6.

26. Fine PG, Portenoy RK, Ad Hoc Expert Panel on Evidence Review and Guidelines for Opioid Rotation. Expert panel on evidence review and guidelines for opioid rotation. establishing « best practices » for opioid rotation: conclusions of an expert panel. J Pain Symptom Manag. 2009;38(3):418-25.

27. Scott LJ, Perry CM. Tramadol: a review of its use in perioperative pain. Drugs. 2000;60(1):139-76.

28. Lee CR, McTavish D, Sorkin EM. Tramadol. A preliminary review of its pharmacodynamic and pharmacokinetic properties, 
and therapeutic potential in acute and chronic pain states. Drugs. 1993;46(2):313-40.

29. Owsiany MT, Hawley CE, Triantafylidis LK, Paik JM. Opioid management in older adults with chronic kidney disease: a review. Am J Med. 2019;132(12):1386-93.

30. Launay-Vacher V, Karie S, Fau J-B, Izzedine H, Deray G. Treatment of pain in patients with renal insufficiency: the World Health Organization three-step ladder adapted. J Pain. 2005;6(3):137-48.

31. Bourquin V, Petignat P-A, Besson M, Piguet V. Analgesia and renal insufficiency. Rev Med Suisse. 2008;4(175):2218-20 (2222-3).

32. Bosilkovska M, Walder B, Besson M, Daali Y, Desmeules J. Analgesics in patients with hepatic impairment: pharmacology and clinical implications. Drugs. 2012;72(12):1645-69.

33. Skinner-Robertson S, Fradette C, Bouchard S, Mouksassi M-S, Varin F. Pharmacokinetics of tramadol and O-desmethyltramadol enantiomers following administration of extendedrelease tablets to elderly and young subjects. Drugs Aging. 2015;32(12):1029-43.

34. Freo U, Furnari M, Ambrosio F, Navalesi P. Efficacy and tolerability of tapentadol for the treatment of chronic low back pain in elderly patients. Aging Clin Exp Res. 2021;33(4):973-82.

35. Schwittay A, Sohns M, Heckes B, Elling C. Tapentadol prolonged release for severe chronic osteoarthritis pain in the elderly - a Subgroup Analysis of Routine Clinical Practice Data. Pain Res Manag. 2020;2020:5759265.

36. Bradford LD. CYP2D6 allele frequency in European Caucasians, Asians, Africans and their descendants. Pharmacogenomics. 2002;3(2):229-43.

37. Dean L. Tramadol Therapy and CYP2D6 Genotype. In: Pratt VM, McLeod HL, Rubinstein WS, Scott SA, Dean LC, Kattman BL, et al., éditeurs. Medical Genetics Summaries [Internet]. Bethesda (MD): National Center for Biotechnology Information (US); 2012 [cited 22 dec 2020]. http://www.ncbi.nlm.nih.gov/ books/NBK315950/. Accessed 22 Dec 2020

38. Swen JJ, Nijenhuis M, de Boer A, Grandia L, Maitlandvan der Zee AH, Mulder H, et al. Pharmacogenetics: from bench to byte-an update of guidelines. Clin Pharmacol Ther. 2011;89(5):662-73.

39. Veal FC, Peterson GM. Pain in the frail or elderly patient: does tapentadol have a role? Drugs Aging. 2015;32(6):419-26.

40. Qaseem A, Wilt TJ, McLean RM, Forciea MA, Clinical Guidelines Committee of the American College of Physicians. Noninvasive treatments for acute, subacute, and chronic low back pain: a clinical practice guideline from the American College of Physicians. Ann Intern Med. 2017;166(7):514-30.

41. Chou R, Gordon DB, de Leon-Casasola OA, Rosenberg JM, Bickler S, Brennan T, et al. Management of Postoperative Pain: A Clinical Practice Guideline From the American Pain Society, the American Society of Regional Anesthesia and Pain Medicine, and the American Society of Anesthesiologists' Committee on Regional Anesthesia, Executive Committee, and Administrative Council. J Pain. 2016;17(2):131-57.

42. Marcou TA, Marque S, Mazoit J-X, Benhamou D. The median effective dose of tramadol and morphine for postoperative patients: a study of interactions. Anesth Analg. 2005;100(2):469-74.

43. Wang X, Narayan SW, Penm J, Patanwala AE. Efficacy and Safety of Tapentadol Immediate Release for Acute Pain: A Systematic Review and Meta-analysis. Clin J Pain. 2020;36(5):399-409.

44. Malonne H, Coffiner M, Sonet B, Sereno A, Vanderbist F. Efficacy and tolerability of sustained-release tramadol in the treatment of symptomatic osteoarthritis of the hip or knee: a multicenter, randomized, double-blind, placebo-controlled study. Clin Ther. 2004;26(11):1774-82.
45. Fishman RL, Kistler CJ, Ellerbusch MT, Aparicio RT, Swami SS, Shirley ME, et al. Efficacy and safety of 12 weeks of osteoarthritic pain therapy with once-daily tramadol (Tramadol Contramid OAD). J Opioid Manag. 2007;3(5):273-80.

46. Burch F, Fishman R, Messina N, Corser B, Radulescu F, Sarbu A, et al. A comparison of the analgesic efficacy of Tramadol Contramid OAD versus placebo in patients with pain due to osteoarthritis. J Pain Symptom Manage. 2007;34(3):328-38.

47. Toupin April K, Bisaillon J, Welch V, Maxwell LJ, Jüni P, Rutjes AW, et al. Tramadol for osteoarthritis. Cochrane Database Syst Rev. 2019;5:CD005522.

48. Afilalo M, Etropolski MS, Kuperwasser B, Kelly K, Okamoto A, Van Hove I, et al. Efficacy and safety of Tapentadol extended release compared with oxycodone controlled release for the management of moderate to severe chronic pain related to osteoarthritis of the knee: a randomized, double-blind, placebo- and active-controlled phase III study. Clin Drug Investig. 2010;30(8):489-505.

49. Buynak R, Shapiro DY, Okamoto A, Van Hove I, Rauschkolb C, Steup A, et al. Efficacy and safety of tapentadol extended release for the management of chronic low back pain: results of a prospective, randomized, double-blind, placebo- and active-controlled Phase III study. Expert Opin Pharmacother. 2010;11(11):1787-804.

50. Afilalo M, Morlion B. Efficacy of tapentadol ER for managing moderate to severe chronic pain. Pain Phys. 2013;16(1):27-40.

51. Santos J, Alarcão J, Fareleira F, Vaz-Carneiro A, Costa J. Tapentadol for chronic musculoskeletal pain in adults. Cochrane Database Syst Rev. 2015;5:CD009923.

52. Oliveira CB, Maher CG, Pinto RZ, Traeger AC, Lin C-WC, Chenot J-F, et al. Clinical practice guidelines for the management of non-specific low back pain in primary care: an updated overview. Eur Spine J. 2018;27(11):2791-803.

53. Kolasinski SL, Neogi T, Hochberg MC, Oatis C, Guyatt G, Block J, et al. 2019 American College of Rheumatology/Arthritis Foundation Guideline for the Management of Osteoarthritis of the Hand, Hip, and Knee. Arthritis Rheumatol. 2020;72(2):220-33.

54. Wiffen PJ, Derry S, Moore RA. Tramadol with or without paracetamol (acetaminophen) for cancer pain. Cochrane Database Syst Rev. 2017;5:CD012508.

55. Rodriguez RF, Bravo LE, Castro F, Montoya O, Castillo JM, Castillo MP, et al. Incidence of weak opioids adverse events in the management of cancer pain: a double-blind comparative trial. J Palliat Med. 2007;10(1):56-60.

56. Leppert W, Majkowicz M. The impact of tramadol and dihydrocodeine treatment on quality of life of patients with cancer pain. Int J Clin Pract. 2010;64(12):1681-7.

57. Bandieri E, Romero M, Ripamonti CI, Artioli F, Sichetti D, Fanizza C, et al. Randomized trial of low-dose morphine versus weak opioids in moderate cancer pain. J Clin Oncol. 2016;34(5):436-42.

58. Carmona-Bayonas A, Jiménez Fonseca P, Virizuela EJ. Tapentadol for cancer pain management: a narrative review. Pain Pract. 2017;17(8):1075-88.

59. Imanaka K, Tominaga Y, Etropolski M, van Hove I, Ohsaka M, Wanibe M, et al. Efficacy and safety of oral tapentadol extended release in Japanese and Korean patients with moderate to severe, chronic malignant tumor-related pain. Curr Med Res Opin. 2013;29(10):1399-409.

60. Imanaka K, Tominaga Y, Etropolski M, Ohashi H, Hirose K, Matsumura T. Ready conversion of patients with well-controlled, moderate to severe, chronic malignant tumor-related pain on other opioids to tapentadol extended release. Clin Drug Investig. 2014;34(7):501-11.

61. Kress HG, Koch ED, Kosturski H, Steup A, Karcher K, Lange $\mathrm{B}$, et al. Tapentadol prolonged release for managing moderate 
to severe, chronic malignant tumor-related pain. Pain Phys. 2014;17(4):329-43.

62. Wiffen PJ, Derry S, Naessens K, Bell RF. Oral tapentadol for cancer pain. Cochrane Database Syst Rev. 2015;9:CD011460.

63. Alam U, Sloan G, Tesfaye S. Treating Pain in Diabetic Neuropathy: Current and Developmental Drugs. Drugs. 2020;80(4):363-84.

64. Desai B, Freeman E, Huang E, Hung A, Knapp E, Breunig IM, et al. Clinical value of tapentadol extended-release in painful diabetic peripheral neuropathy. Expert Rev Clin Pharmacol. 2014;7(2):203-9.

65. Harati Y, Gooch C, Swenson M, Edelman S, Greene D, Raskin P, et al. Double-blind randomized trial of tramadol for the treatment of the pain of diabetic neuropathy. Neurology. 1998;50(6):1842-6.

66. Boureau F, Legallicier P, Kabir-Ahmadi M. Tramadol in postherpetic neuralgia: a randomized, double-blind, placebo-controlled trial. Pain. 2003;104(1-2):323-31.

67. Sindrup SH, Konder R, Lehmann R, Meier T, Winkel M, Ashworth J, et al. Randomized controlled trial of the combined monoaminergic and opioid investigational compound GRT9906 in painful polyneuropathy. Eur J Pain. 2012;16(6):849-59.

68. Norrbrink $\mathrm{C}$, Lundeberg T. Tramadol in neuropathic pain after spinal cord injury: a randomized, double-blind, placebo-controlled trial. Clin J Pain. 2009;25(3):177-84.

69. Duehmke RM, Derry S, Wiffen PJ, Bell RF, Aldington D, Moore RA. Tramadol for neuropathic pain in adults. Cochrane Database Syst Rev. 2017;6:CD003726.

70. Mu A, Weinberg E, Moulin DE, Clarke H. Pharmacologic management of chronic neuropathic pain: review of the Canadian Pain Society consensus statement. Can Fam Physician. 2017;63(11):844-52.

71. Bates D, Schultheis BC, Hanes MC, Jolly SM, Chakravarthy KV, Deer TR, et al. A comprehensive algorithm for management of neuropathic pain. Pain Med. 2019;20(Suppl 1):S2-12.

72. Finnerup NB, Attal N, Haroutounian S, McNicol E, Baron R, Dworkin RH, et al. Pharmacotherapy for neuropathic pain in adults: a systematic review and meta-analysis. Lancet Neurol. 2015; 14(2):162-73.

73. Finnerup NB, Attal N. Tapentadol prolonged release in the treatment of neuropathic pain related to diabetic polyneuropathyauthors' reply. Lancet Neurol. 2015;14(7):685-6.

74. Rosenthal NR, Silverfield JC, Wu S-C, Jordan D, Kamin M, CAPSS-105 Study Group. Tramadol/acetaminophen combination tablets for the treatment of pain associated with osteoarthritis flare in an elderly patient population. J Am Geriatr Soc. 2004;52(3):374-80.

75. Vorsanger G, Xiang J, Jordan D, Farrell J. Post hoc analysis of a randomized, double-blind, placebo-controlled efficacy and tolerability study of tramadol extended release for the treatment of osteoarthritis pain in geriatric patients. Clin Ther. 2007;29(Suppl):2520-35.

76. Biondi DM, Xiang J, Etropolski M, Moskovitz B. Tolerability and efficacy of tapentadol extended release in elderly patients $\geq$ 75 years of age with chronic osteoarthritis knee or low back pain. J Opioid Manag. 2015;11(5):393-403.

77. Lange B, Sohns M, Tempero J, Elling C. Efficacy and safety of tapentadol prolonged release formulation in the treatment of elderly patients with moderate-to-severe chronic osteoarthritis knee pain: a pooled analysis of two double-blind, randomized, placebo-, and active-controlled trials. Curr Med Res Opin. 2018;34(12):2113-23.

78. Kern K-U, Sohns M, Heckes B, Elling C. Tapentadol prolonged release for severe chronic osteoarthritis pain in the elderly: improvements in daily functioning and quality of life. Pain Manag. 2020;10(2):85-95.
79. van Ojik AL, Jansen PAF, Brouwers JRBJ, van Roon EN. Treatment of chronic pain in older people: evidence-based choice of strong-acting opioids. Drugs Aging. 2012;29(8):615-25.

80. Pergolizzi JV, LeQuang JA, Taylor R, Ossipov MH, Colucci D, Raffa RB. Designing safer analgesics: a focus on $\mu$-opioid receptor pathways. Expert Opin Drug Discov. 2018;13(10):965-72.

81. Olson KM, Duron DI, Womer D, Fell R, Streicher JM. Comprehensive molecular pharmacology screening reveals potential new receptor interactions for clinically relevant opioids. PLoS ONE. 2019;14(6): 0217371

82. Pasternak GW, Pan Y-X. Mu opioids and their receptors: evolution of a concept. Pharmacol Rev. 2013;65(4):1257-317.

83. Faria J, Barbosa J, Leal S, Afonso LP, Lobo J, Moreira R, et al. Effective analgesic doses of tramadol or tapentadol induce brain, lung and heart toxicity in Wistar rats. Toxicology. 2017;385:38-47.

84. Barbosa J, Faria J, Leal S, Afonso LP, Lobo J, Queirós O, et al. Acute administration of tramadol and tapentadol at effective analgesic and maximum tolerated doses causes hepato- and nephrotoxic effects in Wistar rats. Toxicology. 2017;389:118-29.

85. Cossmann M, Kohnen C, Langford R, McCartney C. Tolerance and safety of tramadol use. Results of international studies and data from drug surveillance. Drugs. 1997;53(Suppl 2):50-62.

86. Stollenwerk A, Sohns M, Heisig F, Elling C, von Zabern D. Review of post-marketing safety data on tapentadol, a centrally acting analgesic. Adv Ther. 2018;35(1):12-30.

87. DeLemos B, Richards HM, Vandenbossche J, Ariyawansa J, Natarajan J, Alexander B, et al. Safety, tolerability, and pharmacokinetics of therapeutic and supratherapeutic doses of tramadol hydrochloride in healthy adults: a Randomized, Double-Blind, Placebo-Controlled Multiple-Ascending-Dose Study. Clin Pharmacol Drug Dev. 2017;6(6):592-603.

88. Petrone D, Kamin M, Olson W. Slowing the titration rate of tramadol $\mathrm{HCl}$ reduces the incidence of discontinuation due to nausea and/or vomiting: a double-blind randomized trial. J Clin Pharm Ther. 1999;24(2):115-23.

89. Montastruc F, Benevent J, Chebane L, Rousseau V, Durrieu G, Sommet A, et al. Vomiting and constipation associated with tramadol and codeine: a comparative study in VigiBase ${ }^{\circledR}$. Eur J Clin Pharmacol. 2018;74(12):1673-4.

90. Moulis F, Rousseau V, Abadie D, Masmoudi K, Micallef J, Vigier C, et al. Serious adverse drug reactions with tramadol reported to the French pharmacovigilance database between 2011 and 2015. Therapie. 2017;72(6):615-24.

91. Wilder-Smith $\mathrm{CH}$, Bettiga A. The analgesic tramadol has minimal effect on gastrointestinal motor function. Br J Clin Pharmacol. 1997;43(1):71-5.

92. Hartrick CT, Rozek RJ. Tapentadol in pain management: a $\mu$-opioid receptor agonist and noradrenaline reuptake inhibitor. CNS Drugs. 2011;25(5):359-70.

93. Nieuwenhuijs D, Bruce J, Drummond GB, Warren PM, Dahan A. Influence of oral tramadol on the dynamic ventilatory response to carbon dioxide in healthy volunteers. $\mathrm{Br} \mathrm{J}$ Anaesth. 2001;87(6):860-5.

94. van der Schrier R, Jonkman K, van Velzen M, Olofsen E, Drewes AM, Dahan A, et al. An experimental study comparing the respiratory effects of tapentadol and oxycodone in healthy volunteers. Br J Anaesth. 2017;119(6):1169-77.

95. Tsutaoka BT, Ho RY, Fung SM, Kearney TE. Comparative toxicity of tapentadol and tramadol utilizing data reported to the national poison data system. Ann Pharmacother. 2015;49(12):1311-6.

96. Navarroza RV, Zamora LD, Navarra SV. Serotonin syndrome masquerading as disease flare in lupus nephritis with end-stage renal disease. Int J Rheum Dis. 2019;22(10):1933-6. 
97. Rickli A, Liakoni E, Hoener MC, Liechti ME. Opioid-induced inhibition of the human 5-HT and noradrenaline transporters in vitro: link to clinical reports of serotonin syndrome. Br J Pharmacol. 2018;175(3):532-43.

98. Gressler LE, Hammond DA, Painter JT. Serotonin syndrome in tapentadol literature: systematic review of original research. J Pain Palliat Care Pharmacother. 2017;31(3-4):228-36.

99. Baldo BA, Rose MA. The anaesthetist, opioid analgesic drugs, and serotonin toxicity: a mechanistic and clinical review. Br J Anaesth. 2020;124(1):44-62.

100. Medicines and Healthcare products Regulatory Agency (UK). Tapentadol (Palexia): risk of seizures and reports of serotonin syndrome when co-administered with other medicines. [Internet]. 2019. https:// assets.publishing.service.gov.uk/government/uploads/system/uploa ds/attachment_data/file/770006/PDF-Jan-2019-publication.pdf

101. Chrétien B, Dolladille C, Hamel-Sénécal L, Sassier M, Faillie JL, Miremont-Salamé G, et al. Comparative study of hypoglycaemia induced by opioids. Is it a class effect? Expert Opin Drug Saf. 2019;18(10):987-92.

102. Juba KM, van Manen RP, Fellows SE. A review of the food and drug administration adverse event reporting system for tramadolrelated hypoglycemia. Ann Pharmacother. 2020;54(3):247-53.

103. Brož J, Brožová K, Malinovská J. Letter to the editor: hypoglycemia and treatment with opioids. Expert Opin Drug Saf. 2019;18(12):1263.

104. Massarella J, Ariyawansa J, Natarajan J, Francke S, Murtaugh T, DeLemos B, et al. Tramadol hydrochloride at steady state lacks clinically relevant QTc interval increases in healthy adults. Clin Pharmacol Drug Dev. 2019;8(1):95-106.

105. Biondi DM, Xiang J, Etropolski M, Moskovitz B. Evaluation of blood pressure and heart rate in patients with hypertension who received tapentadol extended release for chronic pain: a post hoc, pooled data analysis. Clin Drug Investig. 2014;34(8):565-76.

106. Sanders $P$. Tapentadol analgesic interaction with clonidine. Pain Med. 2013;14(6):943-4.

107. Oh C, Rengelshausen J, Mangold B, Etropolski M, Rauschkolb C, Wang SS, et al. A thorough QT/QTc study of multiple doses of tapentadol immediate release in healthy subjects. Int J Clin Pharmacol Ther. 2010;48(10):678-87.

108. Dunn KE, Tompkins DA, Bigelow GE, Strain EC. Efficacy of tramadol extended-release for opioid withdrawal: a randomized clinical trial. JAMA Psychiat. 2017;74(9):885-93.

109. Thiels CA, Habermann EB, Hooten WM, Jeffery MM. Chronic use of tramadol after acute pain episode: cohort study. BMJ. 2019;365:11849.

110. Dart RC, Bartelson BB, Adams EH. Nonmedical use of tapentadol immediate release by college students. Clin J Pain. 2014;30(8):685-92.

111. Khaja M, Lominadze G, Millerman K. Cardiac arrest following drug abuse with intravenous tapentadol: case report and literature review. Am J Case Rep. 2017;18:817-21.

112. Butler SF, McNaughton EC, Black RA. Tapentadol abuse potential: a postmarketing evaluation using a sample of individuals evaluated for substance abuse treatment. Pain Med. 2015;16(1):119-30.

113. Vosburg SK, Severtson SG, Dart RC, Cicero TJ, Kurtz SP, Parrino MW, et al. Assessment of tapentadol API abuse liability with the researched abuse, diversion and addiction-related surveillance system. J Pain. 2018;19(4):439-53.

114. Frost DA, Soric MM, Kaiser R, Neugebauer RE. Efficacy of tramadol for pain management in patients receiving strong cytochrome P450 2D6 inhibitors. Pharmacotherapy. 2019;39(6):724-9.

115. Saarikoski T, Saari TI, Hagelberg NM, Backman JT, Neuvonen $\mathrm{PJ}$, Scheinin M, et al. Effects of terbinafine and itraconazole on the pharmacokinetics of orally administered tramadol. Eur J Clin Pharmacol. 2015;71(3):321-7.

116. Samer CF, Piguet V, Dayer P, Desmeules JA. Genetic polymorphism and drug interactions: their importance in the treatment of pain. Can J Anaesth. 2005;52(8):806-21.

117. Saarikoski T, Saari TI, Hagelberg NM, Neuvonen M, Neuvonen $\mathrm{PJ}$, Scheinin M, et al. Rifampicin markedly decreases the exposure to oral and intravenous tramadol. Eur J Clin Pharmacol. 2013;69(6):1293-301.

118. Ikenberg R, Hertel N, Moore RA, Obradovic M, Baxter G, Conway $\mathrm{P}$, et al. Cost-effectiveness of tapentadol prolonged release compared with oxycodone controlled release in the UK in patients with severe non-malignant chronic pain who failed $1 \mathrm{st}$ line treatment with morphine. J Med Econ. 2012;15(4):724-36.

119. Obradovic M, Ikenberg R, Hertel N, Antoñanzas F, Gálvez R, Liedgens H. Cost-effectiveness of tapentadol in severe chronic pain in Spain: a cost analysis of data from RCTs. Clin Ther. 2012;34(4):926-43.

120. Neil N, Merchant S, Provenzano D, Ogden K, Mody SH. Clinical simulation model of long-acting opioids for treatment of chronic non-cancer pain in the United States. J Med Econ. 2013;16(2):307-17.

121. Kwong WJ, Ozer-Stillman I, Miller JD, Haber NA, Russell MW, Kavanagh S. Cost-effectiveness analysis of tapentadol immediate release for the treatment of acute pain. Clin Ther. 2010;32(10):1768-81.

122. Merchant S, Noe LL, Howe A, Duff S, Gricar J, Ogden K, et al. Budget impact analysis of tapentadol extended release for the treatment of moderate to severe chronic noncancer pain. Clin Ther. 2013;35(5):659-72.

123. Coluzzi F, Ruggeri M. Clinical and economic evaluation of tapentadol extended release and oxycodone/naloxone extended release in comparison with controlled release oxycodone in musculoskeletal pain. Curr Med Res Opin. 2014;30(6):1139-51.

124. Scarpignato C, Gatta L. Comparing tapentadol to oxycodone/ naloxone combination: building castles in the air. Curr Med Res Opin. 2015;31(2):335-8.

125. Sullivan W, Hirst M, Beard S, Gladwell D, Fagnani F, López Bastida J, et al. Economic evaluation in chronic pain: a systematic review and de novo flexible economic model. Eur J Health Econ. 2016;17(6):755-70.

126. Martindale W, Buckingham R. Martindale: the complete drug reference. 40th ed. London: Pharmaceutical Press; 2020. p. 4912p.

127. Palmaro A, Lapeyre-Mestre M. Comparative study of regulatory measures and analgesic consumption in Europe (2005-2015). Paris: French National Agency of Medicine (ANSM); 2017. p. p144. 